\title{
NOTE ON DIACRITICS
}

Please note that the diacritics have been omitted from all Romanian citations. 
